\title{
ANALISIS DAYA DUKUNG FONDASI DANGKAL PADA TANAH BERLAPIS DENGAN MENGGUNAKAN PROGRAM BERBASIS ELEMEN HINGGA
}

\author{
Hansel Ronaldo $^{1}$ dan Andryan Suhendra ${ }^{2}$ \\ ${ }^{1}$ Program Studi Sarjana Teknik Sipil, Universitas Tarumanagara, Jl. Letjen S. Parman No.1 Jakarta \\ hansel.325150186@stu.untar.ac.id \\ ${ }^{2}$ Program Studi Sarjana Teknik Sipil, Universitas Tarumanagara, J1. Letjen S. Parman No.1 Jakarta \\ andryansuhendra@yahoo.com
}

\begin{abstract}
Generally, foundation classified into shallow foundation and deep foundation. Bearing capacity of foundation can be measured by some methods such as Meyerhof method and finite element method. The purpose of this study was to compare the bearing capacity value generated by these methods. The value of foundation bearing capacity affected by several factors, therefore the author wants to analyse some factors such as upper layer thickness, soil consistency and foundation footing. The analysis results show that the bearing capacity of shallow foundation generated by finite element method experiences the biggest difference up to $28 \%$ compared to Meyerhof method. The value of bearing capacity generated on soft-stiff and medium-stiff soil has the largest increase up to $50 \%$ and $161 \%$ respectively compared to soft-medium soil. The value of bearing capacity differs according to the upper layer soil thickness too. At 2,5 meters thick, the value of bearing capacity decrease up to $19 \%$ compared to 2 meters thick and 160\% compared to 1,5 meters thick. In addition, the bearing capacity value also varies depends on the footing type. Square footing was increased $0-17 \%$ compared to rectangular footing.
\end{abstract}

Keywords: shallow foundation; bearing capacity; finite element; Meyerhof

\begin{abstract}
ABSTRAK
Fondasi secara umum terbagi atas fondasi dangkal dan dalam. Ada beberapa metode untuk menganalisa daya dukung fondasi seperti metode Meyerhof dan metode elemen hingga. Dalam penulisan ini penulis ingin membandingkan nilai daya dukung pada metode tersebut. Ada berbagai faktor yang mempengaruhi nilai daya dukung fondasi, oleh karena itu penulis ingin menganalisa beberapa faktor yang mempengaruhi daya dukung fondasi seperti tebal lapisan atas, konsistensi tanah dan bentuk fondasi terhadap daya dukungnya. Dari hasil perbandingan, kapasitas daya dukung dengan menggunakan metode elemen hingga memperoleh hasil lebih besar hingga $28 \%$ jika dibandingkan dengan metode Meyerhof. Kapasitas daya dukung pada tanah lunak-kaku dan sedang-kaku lebih besar hingga 50\% dan 161\% dibandingkan pada tanah lunak-sedang. Kapasitas daya dukung juga berbeda tiap tebal lapisan atas yang ditinjau. Pada tebal lapisan atas sebesar 2,5 meter, kapasitas daya dukungnya lebih kecil hingga 19\% dibandingkan pada tebal lapisan atas sebesar 2 meter dan hingga 160\% dibandingkan pada tebal lapisan atas sebesar 1,5 meter. Bentuk fondasi juga mempengaruhi kapasitas daya dukung. Kapasitas daya dukung pada fondasi bujur sangkar mengalami kenaikan $0-17 \%$ dibandingkan dengan fondasi persegi panjang.
\end{abstract}

Kata kunci: fondasi dangkal; daya dukung; elemen hingga; Meyerhof

\section{PENDAHULUAN}

Fondasi merupakan bagian dari struktur bangunan yang terletak di paling bawah dari suatu konstruksi. Menurut Bowles (1997) fondasi adalah bagian dari suatu sistem rekayasa yang menopang beban dan meneruskan beban serta beratnya sendiri kepada dan kedalam tanah dan batuan yang terletak dibawahnya. Sementara itu, menurut Das (1995) fungsi fondasi ini adalah meneruskan beban konstruksi ke lapisan tanah yang berada di bawah fondasi. Suatu perencanan fondasi dikatakan benar apabila beban yang diteruskan oleh fondasi ke tanah tidak melampaui kekuatan tanah yang bersangkutan. Apabila kekuatan tanah dilampaui, maka penurunan yang berlebihan atau keruntuhan dari tanah akan terjadi. Dalam proses pembangunan konstruksi, fondasi merupakan salah satu bagian struktur terpenting karena berfungsi untuk menopang struktur yang ada diatasnya dan mendistribusikan beban dari 
struktur atas ke tanah. Secara umum fondasi terbagi atas 2 jenis yaitu fondasi dangkal (shallow foundation) dan fondasi dalam (deep foundation). Batasan masalah dalam penelitian ini antara lain jenis fondasi dangkal yang digunakan adalah fondasi tapak berbentuk bujur sangkar dan persegi panjang, penulangan fondasi diabaikan, perhitungan dilakukan dengan menggunakan program dan analisis berdasarkan data tanah, parameter tanah akan dikorelasi berdasarkan data NSPT, lapisan tanah yang akan dianalisis adalah tanah lempung dengan konsistensi lunak-sedang, lunak-kaku dan sedang-kaku, program yang akan digunakan adalah program berbasis elemen hingga dan pemodelan di desain secara 3 dimensi. Rumusan masalah yang akan dibahas dalam penelitian ini adalah analisis daya dukung fondasi dangkal pada tanah berlapis dan pengaruh ketebalan lapisan tanah terhadap daya dukung pondasi dangkal. Sementara itu, tujuan dari penelitian ini adalah membandingkan besar daya dukung tanah berlapis dibawah pondasi dangkal menggunakan program berbasis elemen hingga dan perhitungan manual berdasarkan data tanah dan mengetahui pengaruh ketebalan lapisan tanah terhadap daya dukung fondasi dangkal.

\section{Fondasi dangkal}

Fondasi dangkal adalah jenis fondasi yang memiliki kedalaman relatif dekat dengan permukaan tanah. Fondasi dangkal biasanya digunakan apabila lapisan tanah kerasnya berada tidak jauh dari permukaan tanah. Menurut Terzaghi (1943) fondasi dikategorikan dangkal bilamana lebar fondasi, sama atau lebih besar dari jarak level muka tanah ke fondasi.

\section{Daya dukung fondasi dangkal menurut meyerhof}

Daya dukung fondasi dangkal yang dibahas oleh Terzaghi hanyalah untuk fondasi jalur atau memanjang, fondasi persegi dan fondasi lingkaran, sedangkan untuk fondasi berbentuk persegi panjang belum dibahas. Karena itu Meyerhof (1963) merumuskan rumus daya dukung fondasi dangkal yang baru yaitu:

$$
q u=c^{\prime} N c F c s F c d F c i+D f \cdot \gamma \cdot N q F q s F q d F q i+\frac{1}{2} \gamma \cdot B \cdot N \gamma F \gamma s F \gamma d F \gamma i
$$

dengan $\mathrm{qu}=$ daya dukung ultimate, $\mathrm{c}^{\prime}=$ kohesi tanah, $\mathrm{Df}=$ kedalaman fondasi, $\gamma=$ berat isi tanah, $\mathrm{B}=$ lebar fondasi, $\mathrm{Nc}, \mathrm{Nq}, \mathrm{N} \gamma$ = faktor daya dukung Meyerhof, Fcs,Fqs,F $\gamma \mathrm{s}=$ faktor bentuk, Fcd,Fqd,F $\gamma d=$ faktor kedalaman dan Fci,Fqi.F $\gamma$ i $=$ faktor inklinasi beban.

\section{Daya dukung fondasi dangkal pada tanah lunak ditopang tanah keras}

Menurut Nujid (2014) apabila tebal lapisan atas lebih besar dibandingkan lebar fondasi, maka daya dukung fondasi sama dengan daya dukung lapisan tanah atas saja (homogeneous). Sebaliknya apabila tebal lapisan atas lebih kecil dibandingkan lebar fondasi, maka daya dukung fondasi tidak hanya pada 1 lapisan tanah (inhomogeneous). Dalam menghitung besar daya dukung fondasi dangkal pada tanah berlapis, sebelumnya diperlukan untuk menghitung perbandingan daya dukung antara lapisan tanah atas dengan bawah terlebih dahulu. Menurut Meyerhof (1974) dan Meyerhof dan Hanna (1978) dalam Das (1983), perbandingan antar daya dukung pada lapisan tanah atas dan bawah tersebut bisa dihitung dengan menggunakan rumus yaitu:

$$
\begin{aligned}
& \mathrm{q} 1=c^{\prime} N c(1)+\frac{1}{2} \gamma 1 B N \gamma(1) \\
& \mathrm{q} 2=c^{\prime} N c(2)+\frac{1}{2} \gamma 2 B N \gamma(2)
\end{aligned}
$$

dengan $\mathrm{q} 1$ = daya dukung pada tanah lunak, $\mathrm{q} 2=$ daya dukung pada tanah keras, $\mathrm{c}^{\prime}=$ kohesi tanah, $\gamma=$ berat isi tanah, $\mathrm{B}=$ lebar fondasi dan $\mathrm{Nc}, \mathrm{N} \gamma=$ faktor daya dukung Meyerhof.

Ketika fondasi didukung oleh lapisan tanah lunak yang ditopang oleh lapisan tanah keras, maka perbandingan $\mathrm{q}_{2}$ (lapisan tanah keras) dan $\mathrm{q}_{1}$ (lapisan tanah lunak) akan lebih besar dari satu. Ketika perbandingan antara kedalaman dari dasar fondasi ke lapisan tanah berikutnya $(\mathrm{H})$ dengan lebar fondasi $(\mathrm{B})$ relatif kecil, maka bidang longsor yang ada dalam tanah akan melalui lapisan atas dan lapisan bawah tanah dibawah pondasi yang bersangkutan seperti yang dapat dilihat pada gambar 1 bagian kiri. 


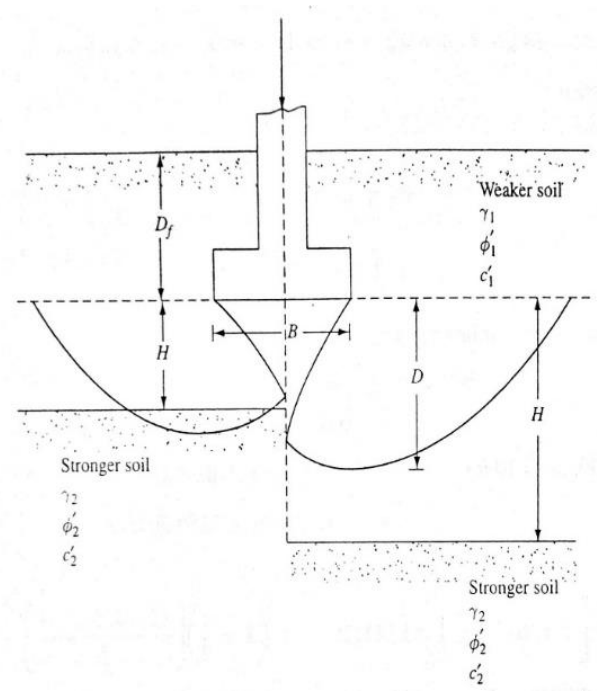

Gambar 1. Fondasi pada tanah lunak ditopang oleh tanah keras (Sumber: Das, 1983)

Untuk kondisi dimana bidang longsor akan berada di kedua lapisan tanah ini, Meyerhof (1974) dan Meyerhof dan Hanna (1978) merumuskan daya dukung batasnya sebagai berikut:

$$
\mathrm{qu}=\mathrm{qt}+(\mathrm{qb}-\mathrm{qt})\left(1-\frac{\mathrm{H}}{\mathrm{D}}\right)^{2} \geq \mathrm{qt}
$$

dengan $\mathrm{qu}=$ daya dukung ultimate $\mathrm{qt}=$ daya dukung ultimate lapisan tanah atas, $\mathrm{qb}=$ daya dukung ultimate lapisan tanah bawah, $\mathrm{H}=$ jarak dari dasar fondasi ke lapisan tanah berikutnya dan $\mathrm{D}=$ kedalaman bidang longsor.

Untuk $\mathrm{q}_{\mathrm{t}}$ dan $\mathrm{q}_{\mathrm{b}}$, Meyerhof dan Hanna (1978) merumuskannya sebagai:

$$
\begin{aligned}
& \mathrm{qt}=c^{\prime} 1 N c(1) F c s(1)+\gamma 1 D f N q(1) F q s(1)+\frac{1}{2} \gamma B N \gamma(1) F \gamma s(1) \\
& \mathrm{qb}=c^{\prime} 2 N c(2) F c s(2)+\gamma 2 D f N q(2) F q s(2)+\frac{1}{2} \gamma B N \gamma(2) F \gamma s(2)
\end{aligned}
$$

dengan $\mathrm{qt}=$ daya dukung ultimate lapisan tanah atas, $\mathrm{qb}=$ daya dukung ultimate lapisan tanah bawah, $\mathrm{c}^{\prime}=\mathrm{kohesi}$ tanah, $\mathrm{Df}=$ kedalaman fondasi, $\gamma=$ berat isi tanah, $\mathrm{B}=$ lebar fondasi, $\mathrm{Nc}, \mathrm{Nq}, \mathrm{N} \gamma=$ faktor daya dukung Meyerhof dan Fcs,Fqs,F $\gamma \mathrm{s}=$ faktor bentuk.

Meyerhof dan Hanna (1978) juga menyimpulkan bahwa nilai D adalah:

- $\mathrm{D}=\mathrm{B}$ untuk loose sand dan clay

- $\mathrm{D}=2 \mathrm{~B}$ untuk dense sand

\section{Program berbasis elemen hingga}

Program berbasis elemen hingga adalah sebuah software yang digunakan untuk menganalisis deformasi, konsolidasi, stabilitas dan aliran air tanah dalam geotechnical engineering. Dalam menggunakan aplikasi geoteknikal, diperlukan pemodelan konstitutif tingkat lanjut untuk simulasi perilaku non-linear, time dependent dan anisotropik tanah. Selain itu karena tanah adalah multi phase material, maka diperlukan prosedur khusus untuk menangani tekanan pori dan saturasi dalam tanah. Analisis yang dilakukan dalam penelitian ini menggunakan program berbasis elemen hingga 3 dimensi. Langkah-langkah dalam input data ke dalam program adalah memasukkan parameter, melakukan desain geometri, menetukan beban, dan menentukan distribusi elemen pada mesh. Kemudian, hasil output dari program antara lain hasil mesh, $\sum$ Mstage, dan $\sum$ Msf.

\section{METODE PENELITIAN}

\section{Pengumpulan data}

Pada penelitian ini, data yang diperoleh berdasarkan hasil asumsi NSPT sesuai dengan konsistensi tanah pada tiap lapisan, kemudian parameter lainnya akan dikorelasikan dengan NSPT yang sudah ditentukan.

\section{Pengelolaan data}


Metode pengelolaan data yang dilakukan untuk menganalisa data menggunakan rumus Meyerhof dan program berbasis elemen hingga. Analisis dilakukan dengan membandingkan besar daya dukung ultimate pada bentuk tapak fondasi yang berbeda, variasi konsistensi tanah yang berbeda dan tebal lapisan atas yang berbeda. Hasil analisis berupa daya dukung ultimate dan hubungan antara beban yang bekerja pada fondasi dengan penurunan elastis.

\section{Diagram alir}

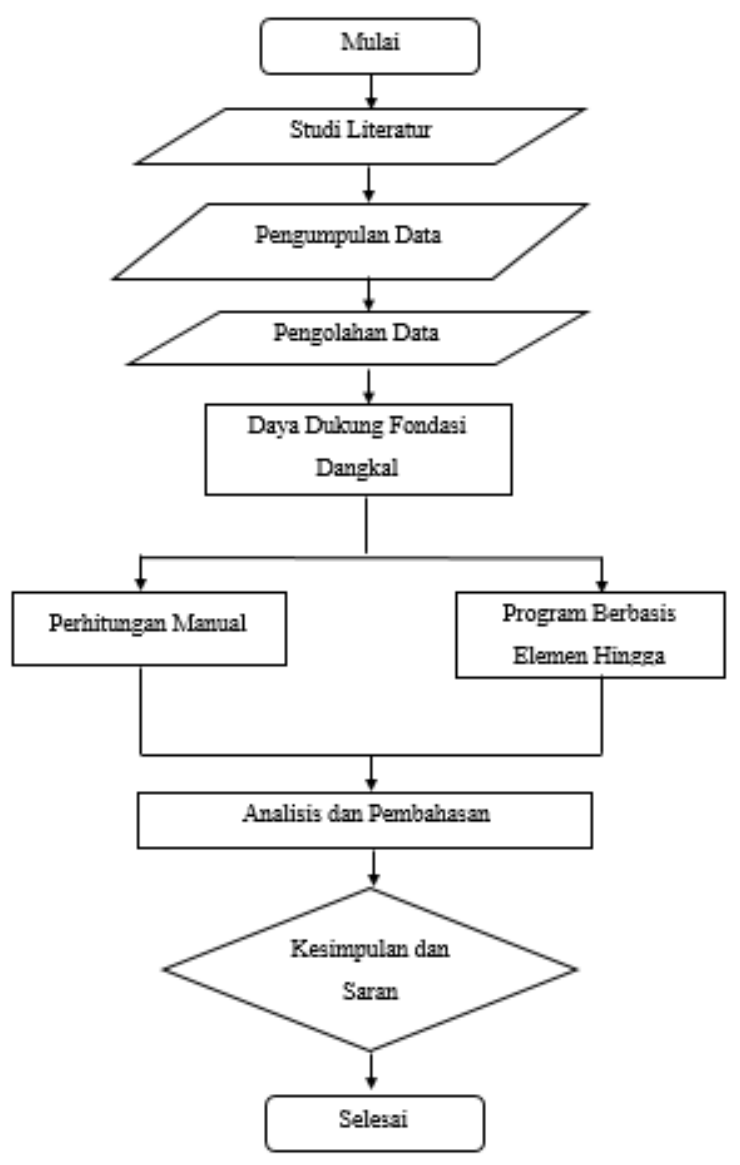

Gambar 2. Diagram alir penelitian

\section{HASIL DAN PEMBAHASAN}

\section{Data fondasi}

Fondasi yang digunakan adalah fondasi dangkal berbentuk bujur sangkar dan persegi panjang dengan ketebalan pelat $300 \mathrm{~mm}$. Fondasi ini menggunakan mutu beton f'c $28 \mathrm{MPa}$ dengan berat jenis beton $(\gamma) 22 \mathrm{kN} / \mathrm{m}^{3}$. Berdasarkan SNI 2847:2013 nilai modulus elastisitas dari fondasi adalah $4700 \sqrt{f^{\prime} c}$.

- $\mathrm{E}^{\prime}$

$$
\begin{aligned}
& =4700 \sqrt{f^{\prime} c} . \\
& =4700 \sqrt{28} . \\
& =24870,0623 \mathrm{MPa}
\end{aligned}
$$


- A (Bujur Sangkar)

$$
\begin{aligned}
\text { - A (Bujur Sangkar) } & =1,5 \mathrm{~m} \times 1,5 \mathrm{~m} \\
\text { - A (Persegi Panjang) } & =2,25 \mathrm{~m}^{2} \\
& =1,8 \mathrm{~m} \times 1,25 \mathrm{~m} \\
& =2,25 \mathrm{~m}^{2}
\end{aligned}
$$

\section{Parameter tanah}

Beberapa parameter tanah yang diperlukan untuk proses analisa diperoleh dari korelasi-korelasi dengan data tanah yang sudah ada. Berikut merupakan hasil ringkasan parameter tanah pada beberapa jenis konsistensi tanah:

Tabel 1. Ringkasan parameter tanah lunak

\begin{tabular}{ccccccccc}
\hline $\mathrm{N}_{\text {SPT }}$ & $\begin{array}{c}\text { Konsistensi } \\
\text { Tanah }\end{array}$ & $\begin{array}{c}\gamma_{\mathrm{sat}} \\
\left(\mathrm{kN} / \mathrm{m}^{3}\right)\end{array}$ & $\begin{array}{c}\mathrm{Su} \\
\left(\mathrm{kN} / \mathrm{m}^{2}\right)\end{array}$ & $\begin{array}{c}\mathrm{c}^{\prime} \\
\left(\mathrm{kN} / \mathrm{m}^{2}\right)\end{array}$ & $\phi$ & e & $v$ & $\begin{array}{c}\mathrm{E}^{\prime} \\
\left(\mathrm{kN} / \mathrm{m}^{2}\right)\end{array}$ \\
\hline 3 & Lunak & 16 & 20 & 4 & $22^{\circ}$ & 1,4 & 0,4 & 2800 \\
\hline
\end{tabular}

Tabel 2. Ringkasan parameter tanah sedang

\begin{tabular}{ccccccccc}
\hline $\mathrm{N}_{\text {SPT }}$ & $\begin{array}{c}\text { Konsistensi } \\
\text { Tanah }\end{array}$ & $\begin{array}{c}\gamma_{\text {sat }} \\
\left(\mathrm{kN} / \mathrm{m}^{3}\right)\end{array}$ & $\begin{array}{c}\mathrm{Su} \\
\left(\mathrm{kN} / \mathrm{m}^{2}\right)\end{array}$ & $\begin{array}{c}\mathrm{c}^{\prime} \\
\left(\mathrm{kN} / \mathrm{m}^{2}\right)\end{array}$ & $\phi$ & $\mathrm{e}$ & $v$ & $\begin{array}{c}\mathrm{E} \\
\left(\mathrm{kN} / \mathrm{m}^{2}\right)\end{array}$ \\
\hline 6 & Sedang & 18 & 45 & 9 & $25^{\circ}$ & 0,9 & 0,3 & 6300 \\
\hline
\end{tabular}

Tabel 3. Ringkasan parameter tanah kaku

\begin{tabular}{ccccccccc}
\hline $\mathrm{N}_{\text {SPT }}$ & $\begin{array}{c}\text { Konsistensi } \\
\text { Tanah }\end{array}$ & $\begin{array}{c}\gamma_{\text {sat }} \\
\left(\mathrm{kN} / \mathrm{m}^{3}\right)\end{array}$ & $\begin{array}{c}\mathrm{Su} \\
\left(\mathrm{kN} / \mathrm{m}^{2}\right)\end{array}$ & $\begin{array}{c}\mathrm{c}^{\prime} \\
\left(\mathrm{kN} / \mathrm{m}^{2}\right)\end{array}$ & $\phi$ & $\mathrm{e}$ & $v$ & $\begin{array}{c}\mathrm{E}^{\prime} \\
\left(\mathrm{kN} / \mathrm{m}^{2}\right)\end{array}$ \\
\hline 12 & Kaku & 20 & 90 & 18 & $29^{\circ}$ & 0,6 & 0,2 & 12600 \\
\hline
\end{tabular}

\section{Daya dukung ultimate fondasi dangkal berdasarkan perhitungan manual}

Berdasarkan rumus daya dukung ultimate pada tanah berlapis menurut Meyerhof dan Hanna, berikut merupakan hasil perhitungan daya dukung ultimate fondasi dangkal:

- Fondasi Bujur Sangkar:

Hasil ringkasan daya dukung fondasi dangkal berbentuk bujur sangkar berdasarkan perhitungan manual dapat dilihat pada tabel 4.

Tabel 4. Daya dukung ultimate fondasi dangkal berbentuk bujur sangkar berdasarkan perhitungan manual

\begin{tabular}{ccc}
\hline $\begin{array}{c}\text { Lapisan } \\
\text { Tanah }\end{array}$ & $\begin{array}{c}\text { Tebal Lapisan Atas } \\
(\mathrm{m})\end{array}$ & $\begin{array}{c}\mathrm{q}_{\mathrm{u}} \\
\left(\mathrm{kN} / \mathrm{m}^{2}\right)\end{array}$ \\
\hline Lunak-Sedang & 1,5 & 488,5168 \\
Lunak-Sedang & 2 & 366,485 \\
Lunak-Sedang & 2,5 & 325,8078 \\
Lunak-Kaku & 1,5 & 1062,123 \\
Lunak-Kaku & 2 & 509,8866 \\
Lunak-Kaku & 2,5 & 325,8078 \\
Sedang-Kaku & 1,5 & 1265,509 \\
Sedang-Kaku & 2 & 835,3046 \\
Sedang-Kaku & 2,5 & 691,9031 \\
\hline
\end{tabular}

- Fondasi Persegi Panjang:

Hasil ringkasan daya dukung fondasi dangkal berbentuk persegi panjang berdasarkan perhitungan manual dapat dilihat pada tabel 5 . 
Tabel 5. Daya dukung ultimate fondasi dangkal berbentuk persegi panjang berdasarkan perhitungan manual

\begin{tabular}{ccc}
\hline $\begin{array}{c}\text { Lapisan } \\
\text { Tanah }\end{array}$ & $\begin{array}{c}\text { Tebal Lapisan Atas } \\
(\mathrm{m})\end{array}$ & $\begin{array}{c}\mathrm{q}_{\mathrm{u}} \\
\left(\mathrm{kN} / \mathrm{m}^{2}\right)\end{array}$ \\
\hline Lunak-Sedang & 1,5 & 544,9596 \\
Lunak-Sedang & 2 & 426,3227 \\
Lunak-Sedang & 2,5 & 364,1795 \\
Lunak-Kaku & 1,5 & 1038,589 \\
Lunak-Kaku & 2 & 613,2594 \\
Lunak-Kaku & 2,5 & 390,4675 \\
Sedang-Kaku & 1,5 & 1213,72 \\
Sedang-Kaku & 2 & 907,027 \\
Sedang-Kaku & 2,5 & 746,3783 \\
\hline
\end{tabular}

\section{Metode elemen hingga}

Berdasarkan hasil analisis pada program berbasis elemen hingga, diperoleh hasil output sebagai berikut:

- Mesh

Setelah melakukan tahap generate mesh, maka program akan menampilkan hasil mesh pada tanah seperti pada gambar 3.

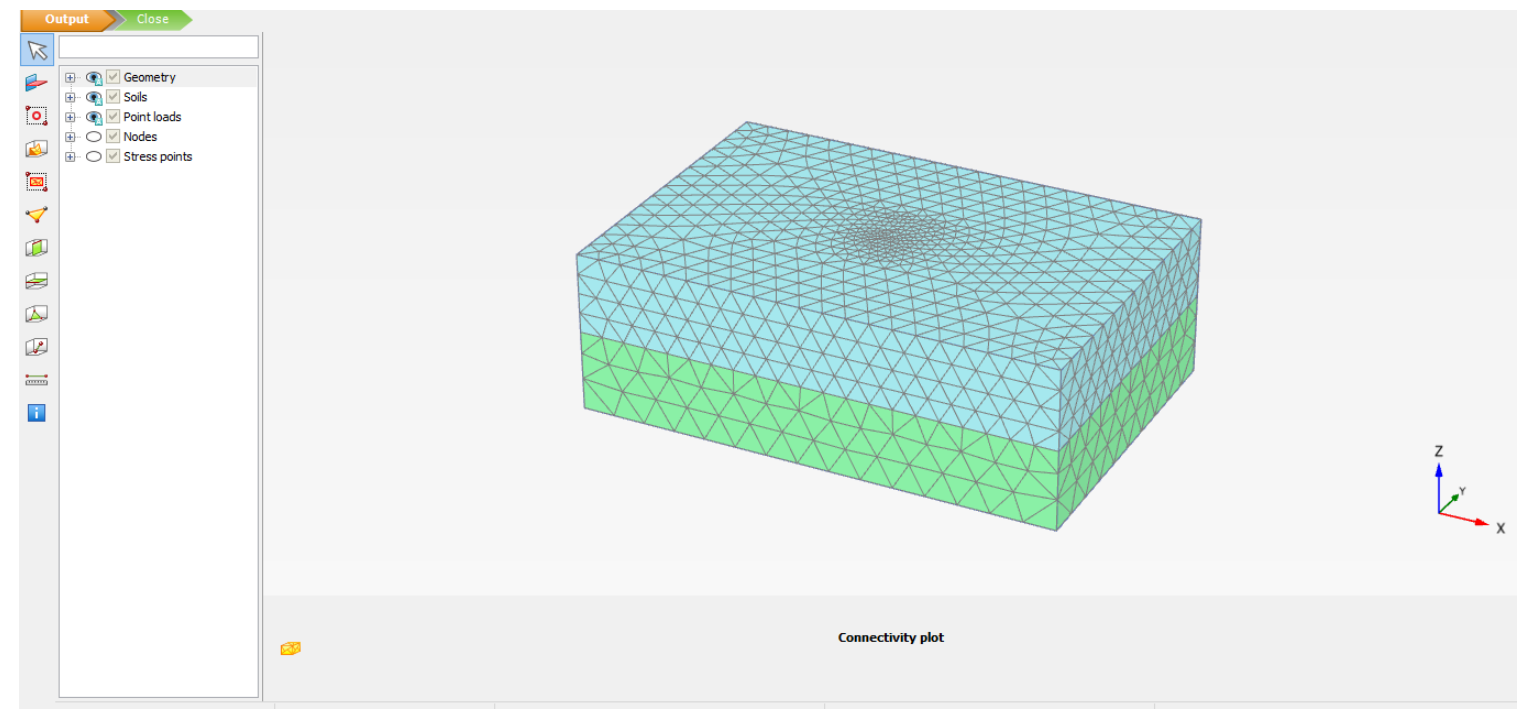

Gambar 3. Hasil mesh pada program

- $\Sigma$ Mstage

$\Sigma$ Mstage harus menyentuh angka 1, apabila $\Sigma$ Mstage tidak mencapai 1 artinya beban yang diberikan pada fondasi terlalu besar sehingga fondasi akan collapse. 


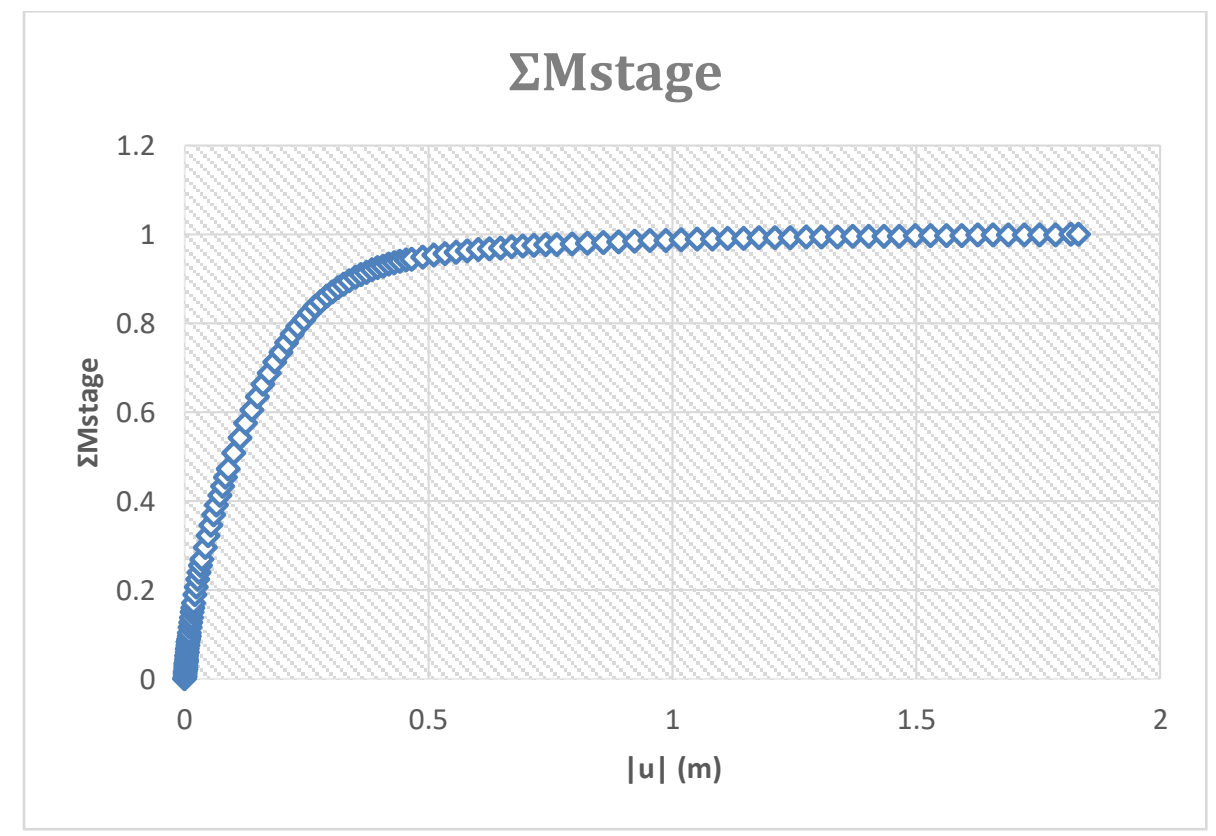

Gambar 4. Kurva $\Sigma$ Mstage

- $\Sigma \mathrm{Msf}$

Dalam menentukan daya dukung ultimate juga perlu melihat $\Sigma$ Msf. $\Sigma$ Msf harus mendekati angka 1 dan di ujung kurva $\Sigma$ Msf harus terlihat konstan seperti pada gambar 5.

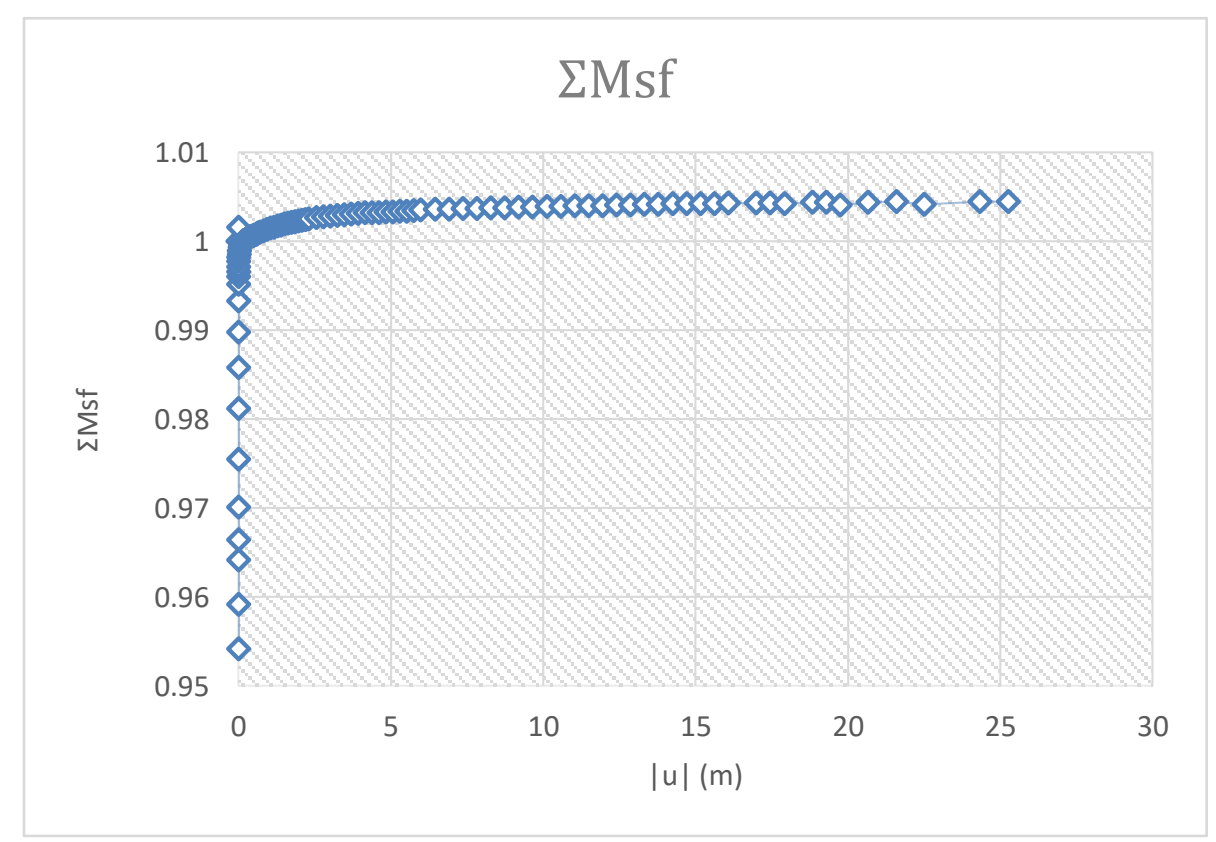

Gambar 5. Kurva $\Sigma$ Msf

\section{Daya dukung ultimate fondasi dangkal berdasarkan program}

Dari hasil $\Sigma$ Mstage dan $\Sigma$ Msf maka dapat diperoleh besar daya dukung ultimate fondasi dangkal. Berikut merupakan hasil daya dukung ultimate fondasi dangkal: 
- Fondasi Bujur Sangkar

Berikut merupakan hasil ringkasan daya dukung ultimate fondasi dangkal berbentuk bujur sangkar berdasarkan program berbasis elemen hingga:

Tabel 6. Daya dukung ultimate fondasi dangkal berbentuk bujur sangkar berdasarkan program

\begin{tabular}{cccc}
\hline $\begin{array}{c}\text { Lapisan } \\
\text { Tanah }\end{array}$ & $\begin{array}{c}\text { Tebal Lapisan Atas } \\
(\mathrm{m})\end{array}$ & $\begin{array}{c}\mathrm{q}_{\mathrm{u}} \\
\left(\mathrm{kN} / \mathrm{m}^{2}\right)\end{array}$ & $\Sigma \mathrm{Msf}$ \\
\hline Lunak-Sedang & 1,5 & 648,31 & 1,005 \\
Lunak-Sedang & 2 & 432,75 & 1,002 \\
Lunak-Sedang & 2,5 & 370,53 & 1,002 \\
Lunak-Kaku & 1,5 & 970,53 & 1,003 \\
Lunak-Kaku & 2 & 441,64 & 1,002 \\
Lunak-Kaku & 2,5 & 370,53 & 1,002 \\
Sedang-Kaku & 1,5 & 1697,2 & 1,006 \\
Sedang-Kaku & 2 & 1083,86 & 1,004 \\
Sedang-Kaku & 2,5 & 908,31 & 1,001 \\
\hline
\end{tabular}

- Fondasi Persegi Panjang

Berikut merupakan hasil ringkasan daya dukung ultimate fondasi dangkal berbentuk persegi panjang berdasarkan program berbasis elemen hingga:

Tabel 7. Daya dukung ultimate fondasi dangkal berbentuk persegi panjang berdasarkan program

\begin{tabular}{cccc}
\hline $\begin{array}{c}\text { Lapisan } \\
\text { Tanah }\end{array}$ & $\begin{array}{c}\text { Tebal Lapisan Atas } \\
(\mathrm{m})\end{array}$ & $\begin{array}{c}\mathrm{q}_{\mathrm{u}} \\
\left(\mathrm{kN} / \mathrm{m}^{2}\right)\end{array}$ & $\Sigma \mathrm{Msf}$ \\
\hline Lunak-Sedang & 1,5 & 603,86 & 1,002 \\
Lunak-Sedang & 2 & 430,53 & 1,004 \\
Lunak-Sedang & 2,5 & 368,31 & 1,005 \\
Lunak-Kaku & 1,5 & 837,2 & 1,003 \\
Lunak-Kaku & 2 & 439,42 & 1,005 \\
Lunak-Kaku & 2,5 & 370,53 & 1,005 \\
Sedang-Kaku & 1,5 & 1559,42 & 1,006 \\
Sedang-Kaku & 2 & 1079,42 & 1,004 \\
Sedang-Kaku & 2,5 & 903,86 & 1,001 \\
\hline
\end{tabular}

\section{Penurunan}

Penurunan yang ditinjau pada penelitian ini adalah penurunan yang terjadi pada dasar fondasi, tepatnya pada tengah fondasi dan ujung fondasi. Berikut merupakan kurva penurunan pada tanah akibat beban yang bekerja.

- Fondasi Bujur Sangkar

Berikut merupakan hasil penurunan fondasi dangkal pada beberapa variasi tebal lapisan atas: 
- Pada tebal lapisan atas 1,5 meter

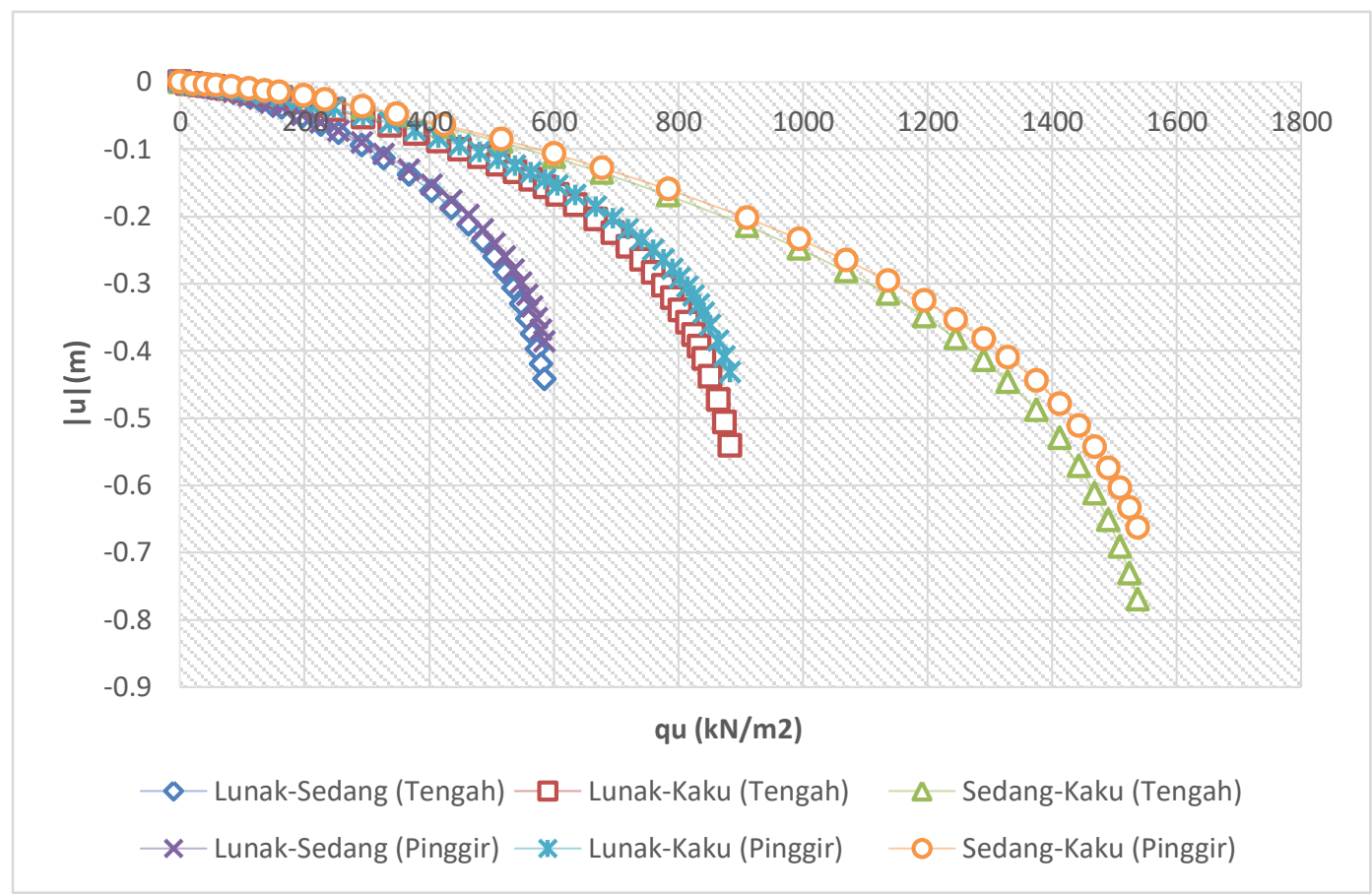

Gambar 6. Kurva beban vs penurunan pada fondasi bujur sangkar (tebal lapisan atas 1,5 meter)

- Pada tebal lapisan atas 2 meter

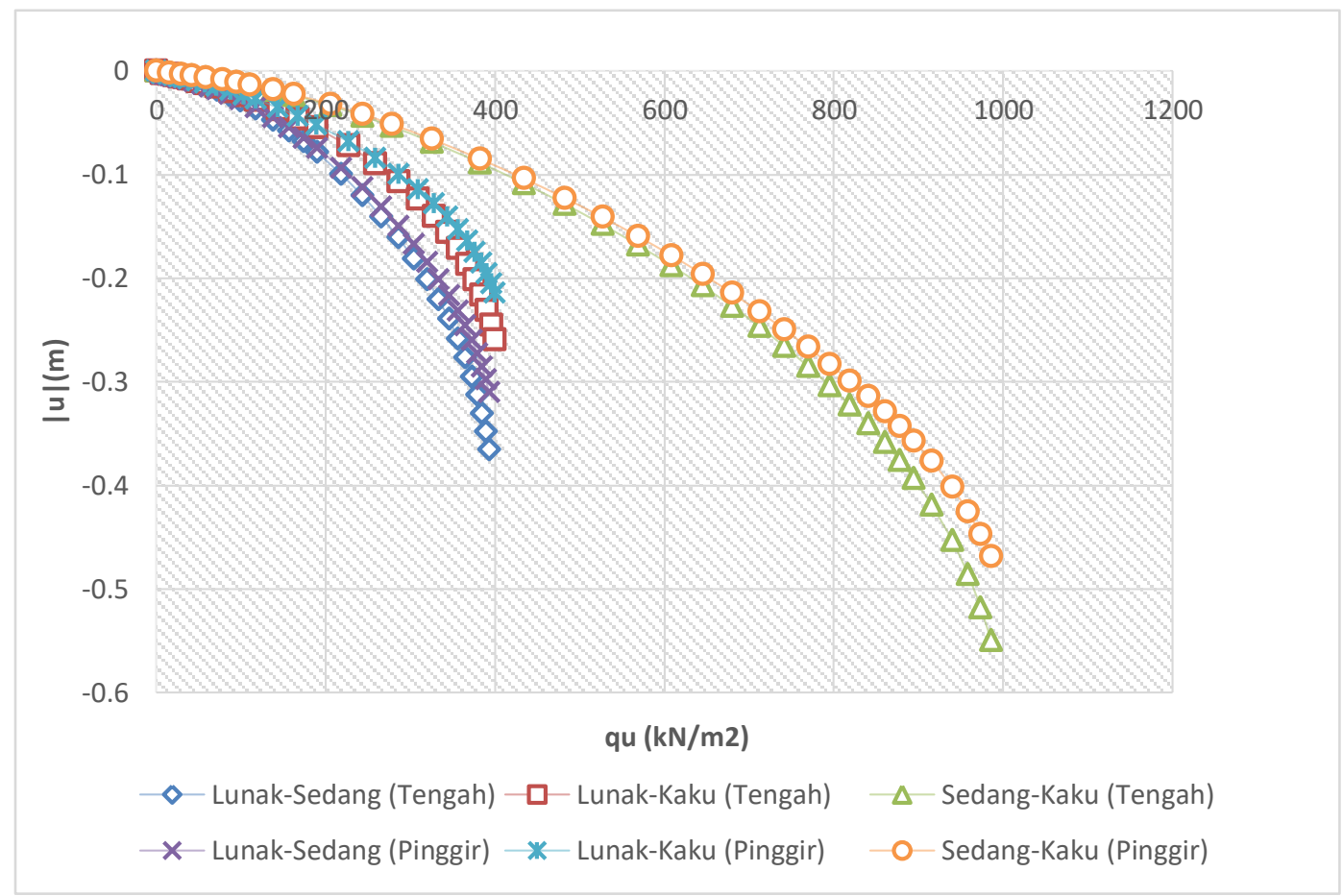

Gambar 7. Kurva beban vs penurunan fondasi bujur sangkar (tebal lapisan atas 2 meter) 


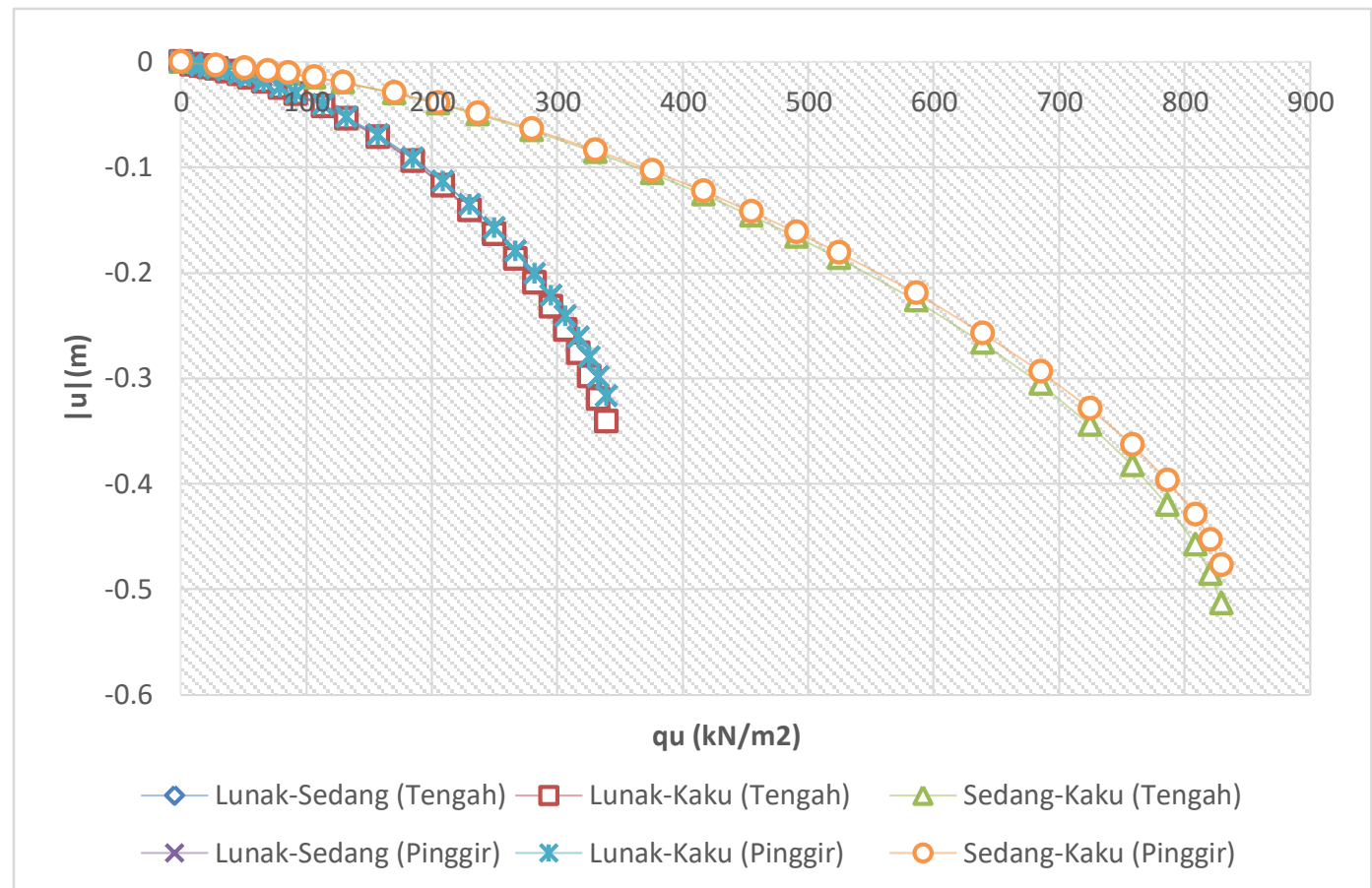

Gambar 8. Kurva beban vs penurunan fondasi bujur sangkar (tebal lapisan atas 2,5 meter)

- Fondasi Persegi Panjang

Berikut merupakan hasil penurunan fondasi dangkal pada beberapa variasi tebal lapisan atas:

- Pada tebal lapisan atas 1,5 meter

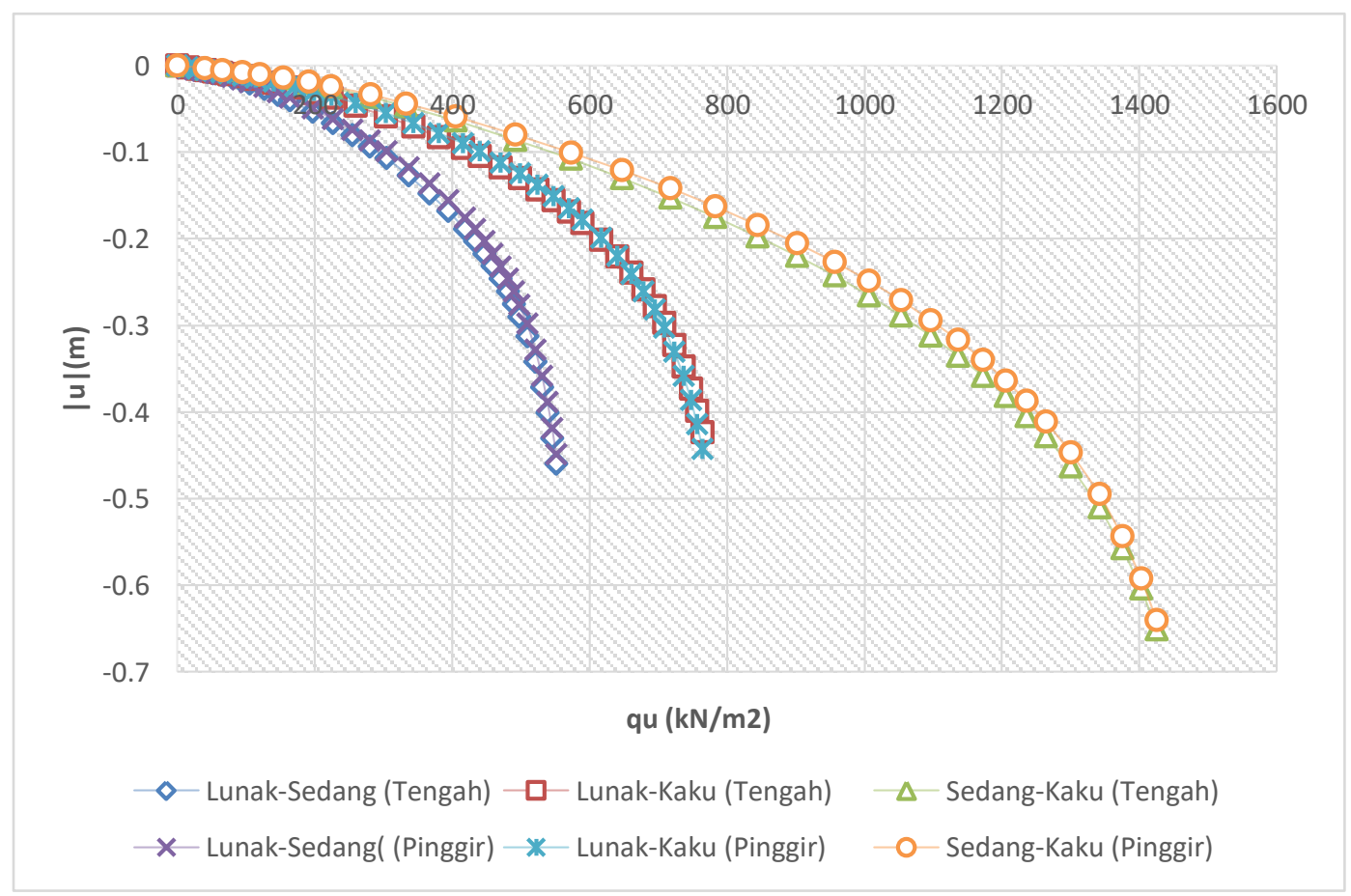

Gambar 9. Kurva beban vs penurunan fondasi persegi panjang (tebal lapisan atas 1,5 meter) 
- Pada tebal lapisan atas 2 meter

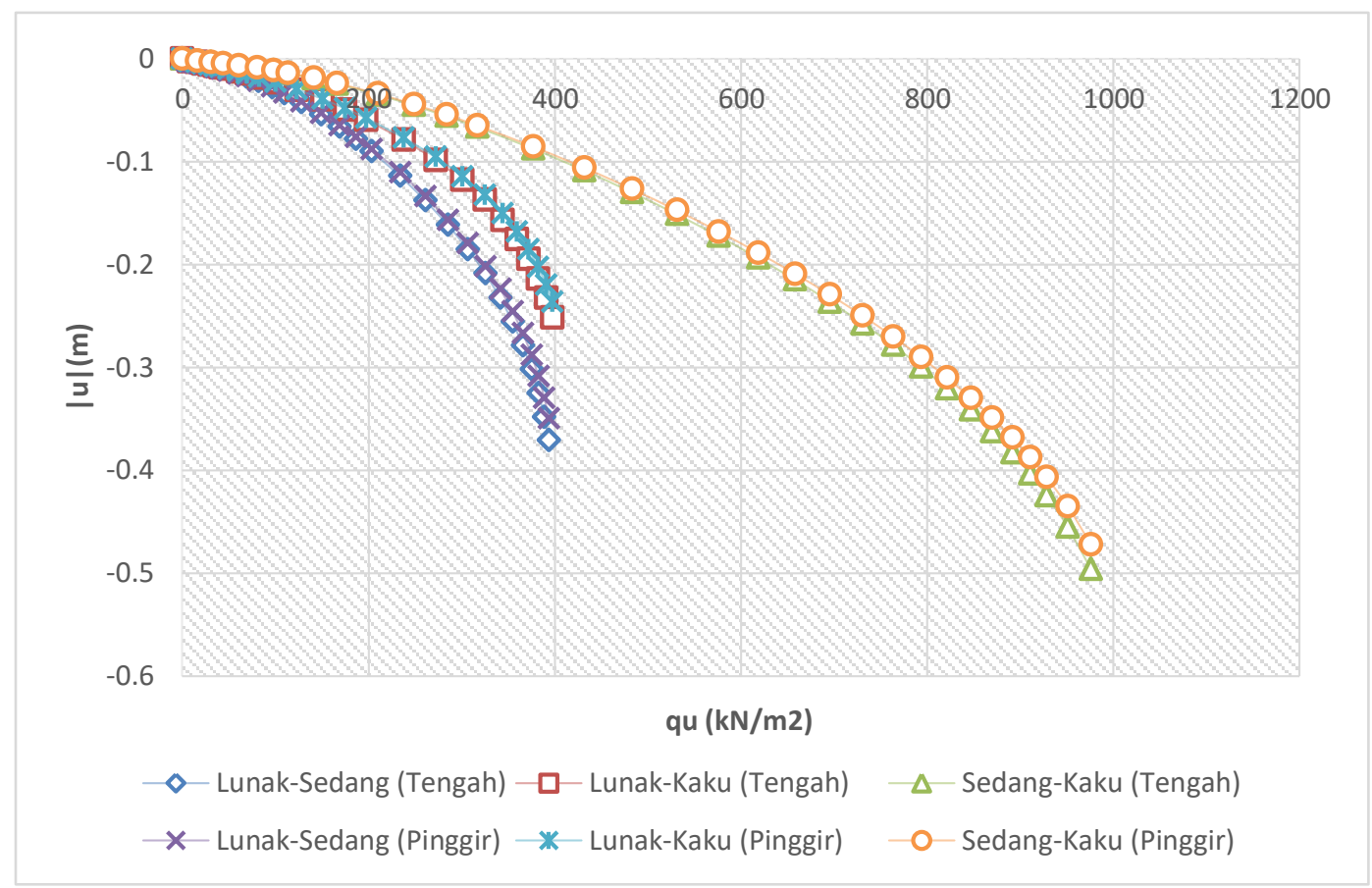

Gambar 10. Kurva beban vs penurunan fondasi persegi panjang (tebal lapisan atas 2 meter)

- Pada tebal lapisan atas 2,5 meter

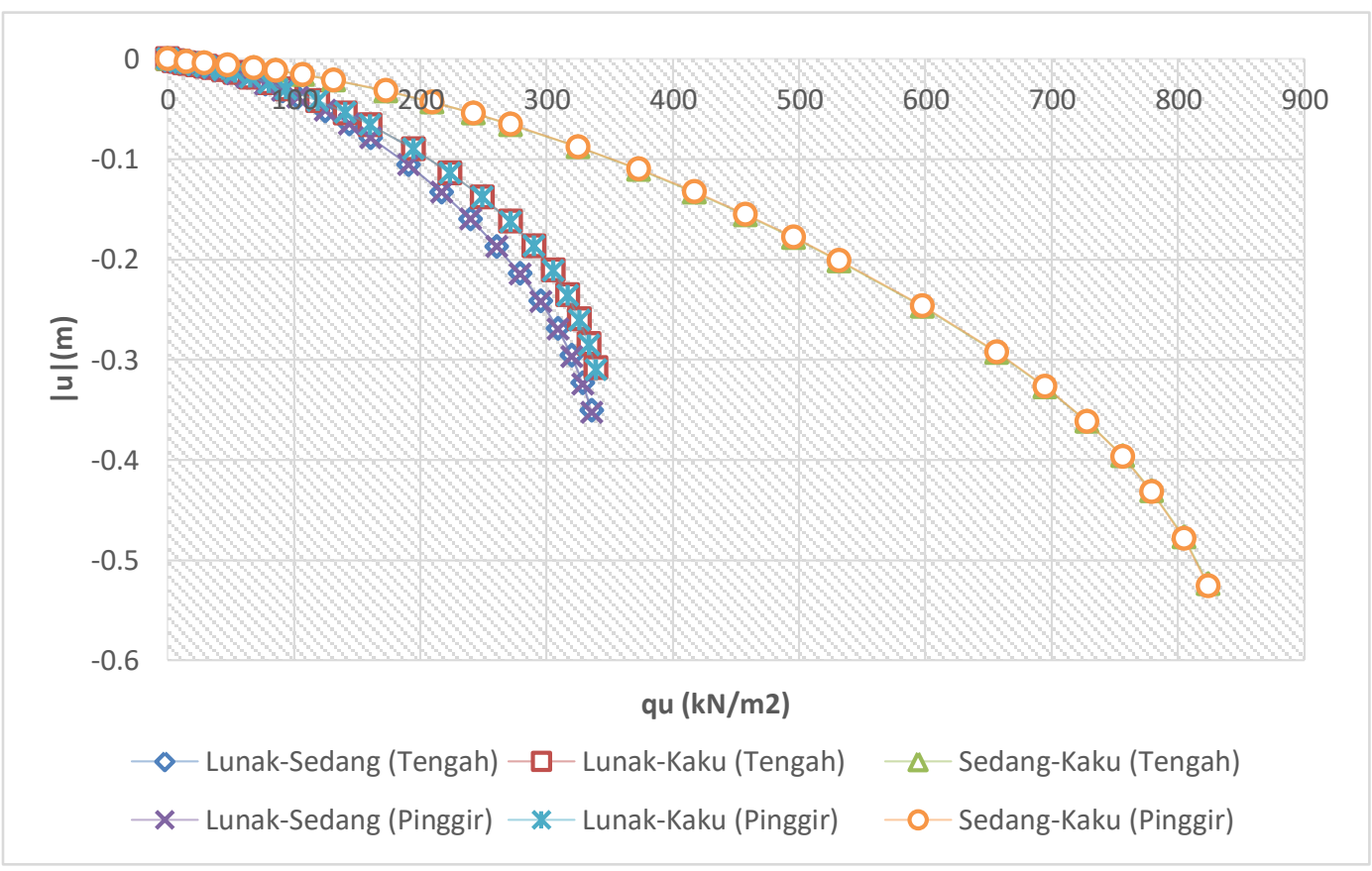

Gambar 11. Kurva beban vs penurunan fondasi persegi panjang (tebal lapisan atas 2,5 meter) 


\section{Perbandingan hasil perhitungan manual dengan program}

Berikut merupakan perbandingan hasil perhitungan manual dengan program:

- Fondasi Bujur Sangkar:

Hasil perbandingan daya dukung ultimate fondasi dangkal berbentuk bujur sngkar pada perhitungan manual dan program dapat dilihat pada tabel 8 .

Tabel 8. Perbandingan daya dukung ultimate manual dengan program pada fondasi bujur sangkar

\begin{tabular}{ccccc}
\hline Lapisan Tanah & $\begin{array}{c}\text { Tebal Lapisan Atas } \\
(\mathrm{m})\end{array}$ & $\begin{array}{c}\mathrm{q}_{\mathrm{u}} \text { manual } \\
\left(\mathrm{kN} / \mathrm{m}^{2}\right)\end{array}$ & $\begin{array}{c}\mathrm{q}_{\mathrm{u}} \text { program } \\
\left(\mathrm{kN} / \mathrm{m}^{2}\right)\end{array}$ & $\begin{array}{c}\text { Perbedaan } \\
(\%)\end{array}$ \\
\hline Lunak-Sedang & 1,5 & 488,5168 & 648,31 & 24,64 \\
Lunak-Kaku & 1,5 & 1062,123 & 970,53 & 8,62 \\
Sedang-Kaku & 1,5 & 1265,509 & 1697,2 & 25,43 \\
Lunak-Sedang & 2 & 366,485 & 432,75 & 15,31 \\
Lunak-Kaku & 2 & 509.8866 & 441,64 & 13,38 \\
Sedang-Kaku & 2 & 835,3046 & 1083,86 & 22,93 \\
Lunak-Sedang & 2,5 & 325,8078 & 370,53 & 12,07 \\
Lunak-Kaku & 2,5 & 325,8078 & 370,53 & 12,07 \\
Sedang-Kaku & 2,5 & 691,9031 & 908,31 & 23,82 \\
\hline
\end{tabular}

- Fondasi Persegi Panjang:

Hasil perbandingan daya dukung ultimate fondasi dangkal berbentuk persegi panjang pada perhitungan manual dan program dapat dilihat pada tabel 9.

Tabel 9. Perbandingan daya dukung ultimate manual dengan program pada fondasi persegi panjang

\begin{tabular}{ccccc}
\hline Lapisan Tanah & $\begin{array}{c}\text { Tebal Lapisan Atas } \\
(\mathrm{m})\end{array}$ & $\begin{array}{c}\mathrm{q}_{\mathrm{u}} \text { manual } \\
\left(\mathrm{kN} / \mathrm{m}^{2}\right)\end{array}$ & $\begin{array}{c}\mathrm{q}_{\mathrm{u}} \text { program } \\
\left(\mathrm{kN} / \mathrm{m}^{2}\right)\end{array}$ & $\begin{array}{c}\text { Perbedaan } \\
(\%)\end{array}$ \\
\hline Lunak-Sedang & 1,5 & 544,9596 & 603,86 & 9,75 \\
Lunak-Kaku & 1,5 & 1038,589 & 837,2 & 19,39 \\
Sedang-Kaku & 1,5 & 1213,72 & 1559,42 & 22,16 \\
Lunak-Sedang & 2 & 426,322 & 430,53 & 0,97 \\
Lunak-Kaku & 2 & 613,2594 & 439,42 & 28,34 \\
Sedang-Kaku & 2 & 907,027 & 1079,42 & 15,97 \\
Lunak-Sedang & 2,5 & 364,1795 & 368,31 & 1,12 \\
Lunak-Kaku & 2,5 & 390,4675 & 370,53 & 5,10 \\
Sedang-Kaku & 2,5 & 746,3783 & 903,86 & 17,42 \\
\hline
\end{tabular}

\section{KESIMPULAN DAN SARAN}

\section{Kesimpulan}

Berdasarkan kajian teknis, analisis dan pembahasan yang dilakukan untuk menganalisa pengaruh ketebalan lapisan tanah atas dan konsistensi tanah terhadap daya dukung fondasi dangkal, dapat disimpulkan bahwa:

1. Perbandingan perhitungan manual dengan perhitungan program baik pada fondasi berbentuk bujur sangkar dan persegi panjang memiliki persentase perbedaan yang bervariasi. Pada variasi tanah lunak-sedang berkisar antara 0,97 - 24,64 \%, pada variasi tanah lunak-kaku berkisar antara 5,10-28,34\%, sedangkan pada variasi tanah sedang-kaku berkisar antara 15,97 - 25,43\%. Persentase perbedaan pada perhitungan manual dan program kemungkinan disebabkan oleh perbedaan pendekatan analisis yaitu perhitungan manual menggunakan pendekatan kesetimbangan gaya sedangkan perhitungan program menggunakan pendekatan tegangan-regangan tanah.

2. Dari hasil perbandingan daya dukung pada tebal lapisan atas 1,5 meter, 2 meter dan 2,5 meter dapat disimpulkan bahwa daya dukung terbesar berada pada variasi tebal lapisan atas 1,5 meter yaitu sebesar $1697,2 \mathrm{kN} / \mathrm{m} 2$ dan daya dukung terkecil berada pada variasi tebal lapisan 2,5 meter yaitu sebesar 368,31 $\mathrm{kN} / \mathrm{m} 2$. Hal ini terjadi karena pada tebal lapisan 1,5 meter, kedalaman bidang longsor terjadi lebih besar pada lapisan bawah dibandingkan lapisan atasnya. Sebaliknya pada tebal lapisan 2,5 meter, kedalaman bidang longsor terjadi lebih besar pada lapisan atas dibandingkan lapisan bawahnya. 
3. Besar daya dukung pada tanah lunak-sedang dan lunak-kaku pada fondasi bujur sangkar dengan tebal lapisan atas 2,5 meter memiliki besaran yang sama yaitu sebesar 370,53 kN/m2. Hal ini terjadi karena jarak dari dasar fondasi ke lapisan tanah berikutnya lebih besar dibandingkan kedalaman bidang longsor, maka beban pada fondasi hanya akan ditahan oleh lapisan tanah atas.

4. Penurunan elastis variasi tanah lunak-sedang pada fondasi berbentuk bujur sangkar dengan tebal lapisan atas 1,5 meter, 2 meter dan 2,5 meter di tengah fondasi adalah sebesar 0,45 meter, 0,39 meter dan 0,35 meter. Dari hasil yang diperoleh maka dapat disimpulkan bahwa besar penurunan elastis pada fondasi dangkal akan berbanding terbalik dengan tebal lapisan tanah. Hal ini juga berlaku untuk variasi konsistensi tanah yang lain dan pada bentuk fondasi persegi panjang.

5. Penurunan yang terjadi pada fondasi dangkal baik pada fondasi berbentuk bujur sangkar dan persegi panjang adalah penurunan elastis. Penurunan konsolidasi tidak terjadi pada project ini karena tipe tanah yang digunakan adalah drained sehingga saat dilakukan pembebanan pada fondasi, tidak terjadi excess pore pressure pada tanah.

6. Penurunan pada tengah fondasi baik pada fondasi berbentuk bujur sangkar dan persegi panjang lebih besar dibandingkan dengan penurunan di tepi fondasi. Hal ini terjadi karena pembebanan pada fondasi dimasukkan berupa point load di tengah fondasi.

\section{Saran}

Dari hasil analisis yang telah dilakukan baik dengan menggunakan perhitungan manual maupun dengan program, penulis memberikan beberapa saran untuk melengkapi kekurangan-kekurangan yang ada, antara lain:

1. Melakukan analisis dengan menggunakan aplikasi lain sebagai pembanding dan dapat melengkapi kekurangan-kekurangan dari program berbasis elemen hingga yang telah digunakan.

2. Melakukan uji laboratorium sehingga parameter dan karakteristik tanah yang diperoleh lebih akurat.

3. Perlu dilakukan analisis dengan model material yang lain pada program agar dapat dibandingkan dengan hasil analisis menggunakan model material mohr coulomb.

4. Melakukan analisis dengan konsistensi tanah yang lain seperti tanah sangat lunak atau tanah keras.

5. Melakukan survei di lapangan sebagai pembanding dengan data tanah agar data yang digunakan lebih akurat.

\section{DAFTAR PUSTAKA}

Badan Standardisasi Nasional. SNI 2847:2013 Persyaratan Beton Struktural, 2013

Bowles, Joseph E. Analisa dan Desain Pondasi Jilid 1 (Diterjemahkan oleh: Pantur Silaban, Ph.D). Jakarta: Penerbit Erlangga, 1997.

Das, Braja M. Mekanika Tanah (Prinsip-Prinsip Rekayasa Geoteknis) Jilid 2 (Diterjemahkan Oleh: Noor Endah dan Indrasurya B. Mochtar). Jakarta: Penerbit Erlangga, 1995.

Das, Braja M. Principle of Geotechnical Engineering Seventh Edition. Stamford: Cengage Learning, 1983.

Nujid, Masyitah M and Mohd R Taha. "A Review of Shallow Foundation on Clay Layered Soils Using Numerical Method." Electronic Journal Geotechnical Engineering (2014): 812.

Terzaghi, Karl. Theoretical Soil Mechanics. New York: John Wiley \& Sons, Inc, 1943 
